www.jmscr.igmpublication.org

Index Copernicus Value: 79.54

ISSN (e)-2347-176x ISSN (p) 2455-0450

crossrefDOI: https://dx.doi.org/10.18535/jmscr/v7i2.129

\title{
Comparison of Physiological Cost Index during Treadmill Walking in Individuals having Different Body Mass Index
}

\author{
Author \\ Dr Namrata Parekh \\ B. N. Patel College of Physiotherapy, Anand, Gujarat, India \\ Email: parekhnamr@gmail.com
}

\begin{abstract}
India is facing dual burden of underweight and overweight. Approximately 43-48\% of Indian men and women of 15-45 years of age group are facing the dual burden out of which 30-36\% people are underweight and 9-13\% people are overweight. PCI is founded on the principle that heart Rate \& walking speed are linearly related to oxygen consumption at sub-maximal levels of exercise. A cross sectional observational study included 48 subject had willing to participate in the study. All subjects divided according to inclusion criteria. Then subjects were asked to performed treadmill walking at their natural walking speed. Then PCI was calculated according to formula. Level of significant was kept 5\%.One-Way Anova test was apply and significance result was founded. Multiple comparisons between all groups was doing using Post hoc analysis in Bonferroni correction test. There was a significant difference in value of physiological cost index in different body mass index. There was relation between BMI and oxygen capacity.
\end{abstract}

Keywords: Physiological cost index, Body mass index, Modified Borg Scale, Treadmill walking, Heart rate.

\section{Introduction}

The physiological cost index (PCI) is a simple tool used to measure energy expenditure during walking. The PCI was established by MacGregor who recognized the need for a simple, functional $\&$ non invasive method of measuring the physiological cost of walking that could be applied in clinical environments. The PCI is founded on the principle that heart rate \& walking speed are linearly related to oxygen consumption at sub-maximal levels of exercise. ${ }^{[1,2]}$

Energy expenditure is traditionally calculated by measuring oxygen consumption which require to collect expired gases, but this methods involves the use of expensive and cumbersome equipment which is unavailable in the clinical environment. ${ }^{[3]}$ The PCI offers a practical alternative. It is an empirical index and defined by MacGregor as follows:

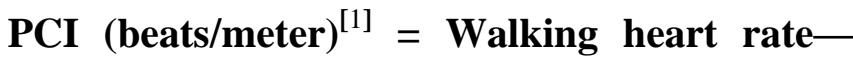
resting heart Rate (beats/min) walking speed $(\mathbf{m} / \mathbf{m i n})$

The PCI, an index of walking of efficiency, has been investigated for reliability and validity. The PCI has reliability ( $\mathrm{r}=0.843-0.944)^{[4]}$ and validity $(\mathrm{r}=0.86) .{ }^{[5]}$ The PCI is closely correlated with METs ( $r=0.88)$ suggests that this index can be useful in energy expenditure. ${ }^{[6]}$ 
The criteria for the PCI are that

1. The subject walks at their " natural ' walking speed where energy efficiency is optimal. ${ }^{[1]}$

2. True resting heart rate is obtained. ${ }^{[2]}$

3. Walking heart rate is measured at steady state or non-steady state or as post exercise heart rate. ${ }^{[2,3]}$

Astrand and Rodahl (1986) have shown that the linear relationship between heart rate and oxygen consumption is fundamental to the PCI and Rose et al. (1991) have shown when calculating PCI the resting heart rate is sensitive and must be measured with accuracy. ${ }^{[3]}$ In our study also included very accuracy measured resting heart rate.

According to the WHO estimates, the undernourished population in the world has declined and is roughly around 1.2 billion, whereas the over nourished population has increased to 1.2 billion. ${ }^{[7]}$

WHO data also show that, globally, there are more than 1 billion adults overweight and 300 million obese people. The problem of obesity is increasing in the developing world with more than 115 million people suffering from obesity related problems. ${ }^{[8]}$

India is facing dual burden of underweight and overweight. Approximately 43-48\% of Indian men and women of 15-45 years of age group are facing the dual burden out of which $30-36 \%$ people are underweight and 9-13\% people are overweight. ${ }^{[9]}$ Underweight due to under-nourishment is most common problem in developing countries and it is burning issue in our country. ${ }^{[10,11]}$ Though underweight is commonly seen in rural areas, it is not uncommon in urban areas. Obesity has reached epidemic proportions in India in the 21st century, affecting $5 \%$ of the country's population. ${ }^{[12]}$ Urbanization and modernization has been associated with obesity. ${ }^{[13]}$

The prevalence of overweight and obesity in urban population of Jamnagar was found to be $22.04 \%$ and $5.20 \%$, respectively. ${ }^{[14]}$
Hippocrates (b. 460-377 BC), the ancient Greek physician regarded as the Father of Medicine, taught that obesity is a health risk and considered it a cause of disease that lead to death. "Obesity refers to the over fat condition that accompanies a constellation of co-morbidities that includes one or all of the components of the obese syndrome."

Obese syndrome includes glucose intolerance, insulin resistance, dyslipidemia, Type 2 diabetes, hypertension, elevated plasma leptin concentration, increased visceral adipose tissue, and increased risk of coronary heart disease and cancer. ${ }^{[15]}$ Complication with the heart is one of the more commonly highlighted secondary effects of obesity. In obese individuals, atherosclerosis, which is a hardening of the arteries, is ten times more present than in individuals who are not obese. This can lead to coronary artery disease, which is another prevalent health effect associated with obesity. ${ }^{[16]}$ The Body Mass Index (BMI) is an index of weight to height $(\mathrm{kg} / \mathrm{m} 2)$ and is considered to be the most useful indicator of health risks associated with both overweight and underweight. ${ }^{[17,18]}$

The international classification of adult BMI according to $\mathrm{WHO}^{[19]}$.

\begin{tabular}{|l|c|}
\hline CLASSIFICATION & $\mathrm{BMI}\left(\mathrm{Kg} / \mathrm{m}^{2}\right)$ \\
\hline UNDERWEIGHT & $<18.5$ \\
\hline NORMAL & $18.50-24.99$ \\
\hline OVERWEIGHT & $\geq 25.00$ \\
\hline OBESE & $\geq 30.00$ \\
\hline OBESE CLASS I & $30.00-34.99$ \\
\hline OBESE CLASS II & $35.00-39.99$ \\
\hline OBESE CLASS III & $\geq 40.00$ \\
\hline
\end{tabular}

Classification of BMI according to revised Indian Guideline $^{[20]}$

\begin{tabular}{|l|l|}
\hline CLASSIFICATION & $\mathrm{BMI}\left(\mathrm{kg} / \mathrm{m}^{2}\right)$ \\
\hline UNDERWEIGHT & $<18.5$ \\
\hline NORMAL & $18.50-22.9$ \\
\hline OVERWEIGHT & $23.0-24.9$ \\
\hline OBESE & $\geq 25.0$ \\
\hline
\end{tabular}

Perception of effort also known as perceived exertion or sense of effort refers to the conscious sensation of how hard, heavy and strenuous a physical task is. This perception depends mainly on feeling of effort in the active limbs and 
sensation of heavy breathing. Perceived exertion accurately reflects relative exercise intensity, which depends on two factors; absolute work load and individual's exercise capacity. ${ }^{[21]}$

Sharma, H et al(2016)," in the study Correlation between six Minute walk test and physiological cost index in healthy Indian females." suggested that increase in heart rate after exercise was positively correlated with increase PCI value. They also suggested that increase BMI value was positively correlated with increase PCI value. In any physical activity, a large proportion of the energy was used to move the body weight and the metabolic cost was directly related to body weight. $^{[22]}$

The aim of the study is to measure energy expenditure during treadmill walking, effect of BMI on energy expenditure and thus, to compare physiological cost index during treadmill Walking in Underweight, Normal, Overweight \& Obese individuals.

\section{Methods}

48 subjects 20-40 years between both gender who had given written informed consent form were included in the study by purposive sampling technique. Those who have any cardiovascular, vestibular, muscular skeletal, and neurological disease were excluded in the study. A cross sectional study included 48 subjects BMI were calculated, and then accordingly were distributed to the respected groups. i.e, Group 1. Underweight individuals. Group 2. Normal individuals . Group 3. Overweight individuals. Group 4. Obese individuals. Before starting procedure explain modified borg scale and natural walking speed. Explain subjects that they perform walking and not running. Subject 's resting heart rate \& Modified Borg scale (rating of perceived exertion) were taken to access hemodynamic stability. Resting heart rate were noted by pulse oximetry. To measure resting heart rate subjects rest in a chair for $5 \mathrm{~min}$ for stabilization of the heart rate. Resting heart rate were recorded by taking every 10 second heart rate for $2 \mathrm{~min}$ during initial resting period \& average heart rate were taken ${ }^{[24]}$ Then subjects were asked to perform treadmill walking at their natural walking speed. ${ }^{[25]}$ Subjects began the walking speed were $2 \mathrm{~km} / \mathrm{h}$. After they started walking they increased speed and corresponding to a perceived exertion level. After they decide their own natural walking speed, they maintain the speed up to they feel exertion level 5 i.e., severe. subjects were asked to stop the walking if they feel exertion level 5 i.e. "severe" according to modified Borg scale. ${ }^{[23,26]}$ Walking heart rate was noted by pulse oximetry. Then after, walking heart rate was calculated as the average heart rate recorded at 10 second interval for the last 30 seconds during walking ${ }^{[24]}$ Also speed of walking \& time taken to reach exertion level of 5 were noted. Then PCI was calculated according to following formula.

\section{PCI (beats/meter) = Walking heart rate- resting heart Rate (beats/min)/ walking speed $(\mathbf{m} / \mathbf{m i n})[1]$}

Same procedure was repeated for Group 2, group $3 \&$ group 4 value of PCI was calculated.

\section{Statistical Analysis}

The result was analyzed using SPSS version 16.0. The level of significance was kept at $\mathrm{p}<0.05$.

The data was screened for normal distribution using Kolmogorov Smirnov normality test and Shapiro-wilk test. Data was normally distributed. Intergroup comparison of physiological cost index in all four group was doing using parametric One Way Anova test. Multiple comparisons between all four groups was doing using Post hoc analysis in Bonferroni correction test.

\section{Result}

48 subjects were included in the study. In Underweight $16.7 \%$ male and $83.3 \%$ female were participated in study. They mean age were 22 . In Normal $33.3 \%$ male and $66.7 \%$ female were participated in study. They mean age were 22 . In Overweight $33.3 \%$ male and $66.7 \%$ female were participated in study. They mean age were 24.In 
Obese $16.7 \%$ male and $83.3 \%$ female were participated in study. They mean age were 25 . Show in table 1 and 2.

Table: 1 Gender Distribution of Individuals.

\begin{tabular}{|l|c|c|}
\hline Group & Male & Female \\
\hline 1 (Underweight) & $16.7 \%$ & $83.3 \%$ \\
\hline 2 (Normal) & $33.3 \%$ & $66.7 \%$ \\
\hline 3 (Overweight) & $33.3 \%$ & $66.7 \%$ \\
\hline 4 (Obese) & $16.7 \%$ & $83.3 \%$ \\
\hline
\end{tabular}

Gender distribution in four group according to percentiles.

Table: 2 Age Distribution of Individuals

\begin{tabular}{|l|c|}
\hline GROUP & MEAN AGE \pm SD \\
\hline Underweight & $22.91 \pm 1.67$ \\
\hline Normal & $22.41 \pm 4.51$ \\
\hline Overweight & $24.41 \pm 3.80$ \\
\hline Obese & $25.33 \pm 4.51$ \\
\hline
\end{tabular}

Mean age distribution in four group.
In study, the mean value of PCI for Underweight was 0.60 beats/meter, Normal was 0.68 beats/meter, Overweight was 0.85 beats/meter, and Obese was 0.92 beats/meter.

There is statistical significant difference in value of physiological cost index between (Underweight and Normal), (Normal and Overweight), (Obese and Underweight), (Obese and Normal), and (Overweight and Underweight) individuals during treadmill walking. There is statistical no significant difference in value physiological cost index between (Overweight and Obese).

PCI value was founded, in this study highest in obese than overweight and normal. Lowest PCI value was founded in underweight individuals.

Table: 3 Comparison of Physiological cost Index between four Groups. ONE -WAY ANOVA

\begin{tabular}{|l|c|c|c|c|}
\hline GROUP & $\begin{array}{c}\text { MEAN } \pm \text { SD } \\
\text { (beats/meter) }\end{array}$ & f VALUE & p VALUE & SIGNIFICANCE \\
\cline { 1 - 2 } 1(Underweight) & $0.60 \pm 0.04$ & \multirow{2}{*}{57.01} & \multirow{2}{*}{0.001} & YES \\
\cline { 1 - 2 } 2 (Normal) & $0.68 \pm 0.06$ & & & \\
\cline { 1 - 2 } 3 (Overweight) & $0.85 \pm 0.06$ & & & \\
\hline
\end{tabular}

Comparison of Physiological Cost Index in Under weight, Normal, Overweight, and Obese individuals. Intergroup comparison is shown Table 3.

One-Way Anova test was applied.
In Table 4 is shown Post hoc analysis was done using Bonferroni correction for multiple comparisons between the groups. Graph 1 shown also comparisons between all the groups.

Table: 4 POST-HOC multiple comparison of mean difference in Physiological Cost Index between the groups.

\begin{tabular}{|l|c|c|c|}
\hline GROUP COMPARISON & MEAN \pm SE & P VALUE & SIGNIFICANCE \\
\hline $\begin{array}{l}1 \text { vs } 2 \\
\text { (Underweight/ Normal) }\end{array}$ & $0.08 \pm 0.02$ & 0.031 & YES \\
\hline $\begin{array}{l}2 \text { vs } 3 \\
\text { (Normal/ Overweight) }\end{array}$ & $0.17 \pm 0.02$ & 0.001 & YES \\
\hline $\begin{array}{l}3 \text { vs } 4 \\
\text { (Overweight/Obese) }\end{array}$ & $0.07 \pm 0.02$ & 0.104 & NO \\
\hline $\begin{array}{l}4 \text { vs } 1 \\
\text { (Obese/Underweight) }\end{array}$ & $0.32 \pm 0.02$ & 0.001 & YES \\
\hline $\begin{array}{l}2 \text { vs } 4 \\
\text { (Normal /Obese) }\end{array}$ & $0.24 \pm 0.02$ & 0.001 & YES \\
\hline $\begin{array}{l}3 \text { vs } 1 \\
\text { (Overweight/Underweight) }\end{array}$ & $0.25 \pm 0.02$ & 0.001 & YES \\
\hline
\end{tabular}




\section{$\mathrm{PCl}$ (beats/meter)}

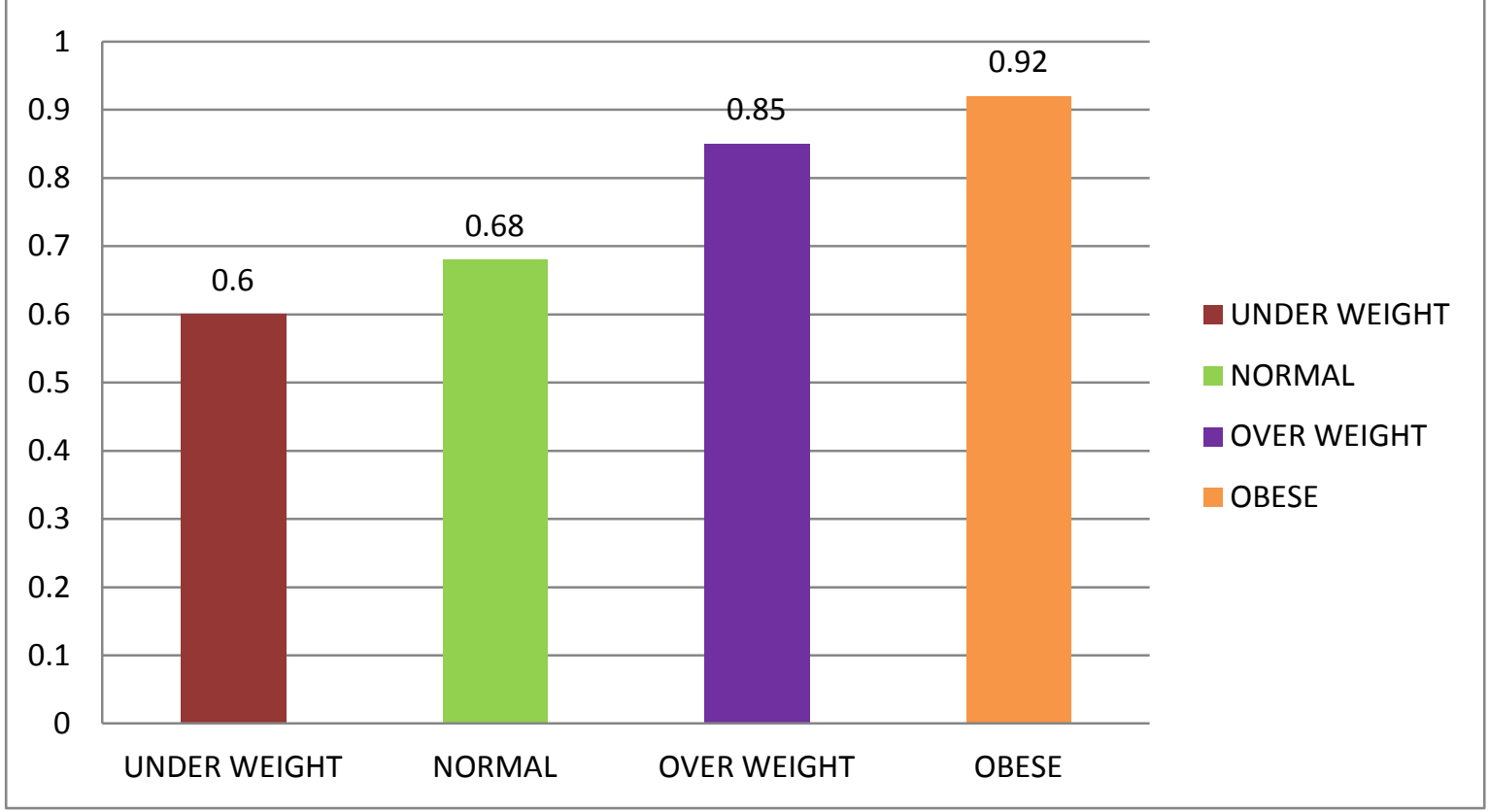

Graph 1: Comparison of Physiological Cost Index between Four Groups

\section{Discussion}

This study was conducted to compare the value of physiological cost index in Underweight, Normal, Overweight, and Obese individuals during treadmill walking. This was done by calculated physiological cost index in different four group.

The Result of this study suggested there is significant difference in value of Physiological cost index between (Underweight and Normal), (Normal and Overweight), (Obese and Underweight), (Obese and Normal), and (Overweight and Underweight) individuals. There are several changes which occurs due to increase body mass index which may affect heart rate and walking speed in individuals, which is responsible for this result.

The hypothesis behind highest PCI value found in obese is that, obese individuals walk slow than normal and most important reason was during treadmill walking heart rate is increased, because of altered cardio respiratory changes in obese and overweight.

In Respiratory system, there is decrease in chest wall compliance associated with the obese individuals accumulation of fat in and around the ribs, diaphragm and the abdomen. Although considerable energy may be spent in overcoming the reduction in chest wall compliance, it accounts for only one-third of the increased work of breathing, remaining energy increase in non elastic work or an inefficiency of the respiratory muscles. Non elastic work is air flow limitation and the airway resistance. Increase work of breathing and increase resistance stimulate breathlessness, due to heart rate increased. Obese individuals in cardiac changes, increase in stroke volume, cardiac output, left ventricular enddiastolic pressure and pulmonary artery pressure. The hypervolemic and hyperdynamic states increase left ventricle work and lead to an increase cardiac mass. The increase in heart mass is predominantly due to an increase in muscle mass of the left ventricle and not due to epicardial or myocardial fat infiltration. ${ }^{\text {[27] }}$

Some study found similar result that the physiological cost of walking was higher in obese boys than non-obese boys. The difference was founded because of HR max is higher in obese boys. ${ }^{\text {[28] }}$

Raymond $\mathrm{C}$ et al suggested in obese adults may prefer to walk slower than normal individuals. The mean net metabolic rate and oxygen consumption 
was $11 \%$ higher for the obese subjects compared with normal weight subjects. Greater body mass and heavier legs increase in net energy expenditure of $15 \%$ (per total kilograms).The mean net metabolic rate was $11 \%$ higher for the obese subjects compared with normal weight subjects. The greater difference in metabolic rate because, in of the greater adiposity (percent fat) of their subjects. The metabolic rate increase with increase BMI. Obese subjects was $36 \mathrm{~kg}$ heavier than the normal weight subjects. ${ }^{[33]}$

Some studies, found in similar results that with slower speeds, the PCI values were high, indicating poor economy. The PCI values decreased to maximum economy as walking speeds increased. And they found PCI values relationship with body weight, gender, walking speed, and leg length. ${ }^{\text {[29] }}$

NHANES (National Health and Nutrition Examination Survey) suggested Obesity is associated with high insulin and leptin levels. High levels of insulin and leptin increase sympathetic nervous system activity and engender increased chronotropy, vasoconstriction, pulse rate and blood pressure. ${ }^{[30]}$

American Heart Association, suggested that obesity was develop imbalance between energy intake and energy expenditure. Energy expended in physical activity. This varies due to differences in body mass. [31]

Study suggested that increase energy expenditure by increasing physical activity, In obesity increase sympathetic nervous system activation lead to increase heart rate and energy expenditure. ${ }^{[32]}$

Increased body mass with increased energy expenditure. In weight bearing exercise like (walking, running) also increased energy expenditure. In obese high energy expenditure, because of extra energy required to lift heavier lower limbs. Heart rate and oxygen consumption are linearly related, so increase heart rate leads to increase energy expenditure. ${ }^{[15]}$

Recently a study 2016, suggested that increase in heart rate after exercise was positively correlated with increase PCI value. They also suggested that increase BMI value was positively correlated with increase PCI value. They concluded any physical activity, a large proportion of the energy was used to move the body weight and the metabolic cost was directly related to body weight. They also suggested that no correlation in VO2max and PCI. They suggested that PCI value directly associated with weight and BMI. ${ }^{[22]}$

\section{Conclusion}

There is statistical significant difference in value of physiological cost index between all group individuals, excepted overweight and obese. The value of physiological cost index is higher in obese and overweight than normal. Lowest Physiological cost index value was found in underweight individuals during treadmill walking.

\section{Conflicts of interest: None}

\section{References}

1. Peebles KC, Woodman-Aldridge AD, Skinner MA. The Physiological cost index In Elderly Subjects During Treadmill AND Floor Walking. New Zealand Journal of Physiotherapy,(2003).31(1):11-16.

2. Maggie J Bailey and Claire M Ratcliffe. Reliability of Physiological cost index Measurements in Walking Normal Subject Using Steady-state, Non- steady-state and Post exercise Heart Rate Recording. Physiotherapy.(1995), vol 81,pg 10.

3. Astrand P \& Rodahl K. Textbook of Work Physiology.3 rd ed. London, England. (1986) pp.372.3

4. Maggie, J, Clarrie. M. Reliability of physiological cost index measured in walking normal subject using steady-state, non-steady state and post exercise heart rate recording. Science direct; vol.81 (10):618-623,2015.

5. Maaeten J. I Jzerman, Anand V.Nene, Feasibility of Physiological cost index As An Outcome Measure for The Assessment of Energy Expenditure During Walking. 
Arch Phys Med Rehabil (2002);83:177782.

6. Hitoshi, Takei Relationship Between Beats Above Baseline Index (BABI) And Physiological Cost Index(PCI) During Walking With Leg Length Discrepancy.J Phys. Ther.Sci.(1996) 8: 13-18,1.

7. Satter N, McConnachie A, Shaper AG, Wannamethee SG, et al. Can metabolic syndrome usefully predict cardiovascular disease and diabetes? Outcome data from two prospective studies. Lancet. 2008;371:1927-1935. 55

8. World Health Organization (WHO) Obesity: Preventing and managing the global epidemic . Last accessed july 2008:Pg:8,9.

9. National Family Health Survey(NFHS-3) 2005-06.Available from: iipsnfhs@ vsnl.com

10. Shah C, Diwan J, Rao P,Bhabhor M,Gokhale P, Mehta H.Assessment of Obesity in School children. Calicut Medical Journal.2008;6(3);

11. Shukla H, Gupta P,Mehta H and Herbert. Descriptive epidemiology of body mass index of an urban adult population in Western India. Journal Epidemiology and Community Health.2002;56:876-880.

12. Rajesh kumari .Obesity in ayurveda in epidemic 2015:pg 5.

13. Yadav K, Krishna A. Changing pattern of diet physical activity and obesity among urban, rural, and slum populations in north India.Obese Rev.2008;9(5):400-8.

14. Vadera BN, Yadav SB,et al. Study on obesity and Influence of dietary factors on the weight status of an adult population in Jamnagar city of Gujarat: A crosssectional analytical study. Indian journal of community medicine.2010;35(4):482-486.

15. McArdle WD, Katch FI. Exercise Physiology: Energy, Nutrition \& Human performance. 7th Edition,2010.pg -780.
16. Health Effects of Obesity. Stanford Hospital \& Clinics,2011. Avaliable Form: http://stanfordhealthcare.org.

17. World Health Organization. Obesity: Preventing and Managing the Global Epidemic. Obesity. Geneva: 2000;pg 200,894.56

18. World Health Organization. Physical Status: The Use and Interpretation of Anthropometry. Geneva:1995;Pg-854.

19. World health Organization. The Asia specific perspective;2004:Avaliable form: www.who.int $>$ bmi.asia.strategies.

20. H.K. Thakkar, S.K.Misra A study on prevalence of obesity among college going girls in arra district of U.P. Indian journal of community health.vol 21;2; june 2010.

21. E Bruce Goldstain, Encyclopaedia of perception ,SAGE publication, London; vol 1:2010.

22. Sharma H, Sarkar A et al Correlation Between Six Minute walk test and Physiological Cost Index in Healthy Indian Females. International Journal of Science and Research. February:2016;5:2.

23. Elisabet Borg: A COMPARISON BETWEEN TWO RATING SCALES FOR PERCEIVED EXERTION: Swedish national center for research in sports.2001.

24. Cheng -Husun Wu .Physiological cost index of walking for normal adults .Department of rehabilitation , Ten-chen General hospital, Jhongi

25. Giorgio Chiaranda et al Treadmill Walking speed and survival predication in men with cardiovascular disease: a 10 -year follow up study. BMJ open-2013:3:10.

26. American association of cardiovascular \& pulmonary rehabilitation guidelines. Third edition. page no: 61 .

27. K Parameswaran, Dc Todd, M Soth. Altered respiratory physiology in obesity. Can Respir J 2006;13(4):203-210.

28. Zaklad Fizjologii Biochemii. The Development changes in Physiological 
cost of locomotion efforts in overweight boys. Pediatr Endocrinol Diabetes Metab:2002:18(2):63-9.

29. Cheng -Husun Wu .Physiological cost index of walking for normal adults .Department of rehabilitation, Ten-chen General hospital, Jhongi.

30. Martins D, Tareen N. The Relationship between body mass index, blood pressure and pulse rate among normotensive and hypertensive participants. NHANES (National Health and Nutrition Examination Survey-3)ell mol Biol 2003 dec:49:8:1305-9.pubmed.

31. Ronald M, Mary W, Barbara J et al American Heart Association, Circulation 1998;98:472-1476.

32. Prabha Setty et al Correlation between Obesity and Cardio Respiratory Fitness. International Journal of Medical Science and Public Health.2013;2:298-302

33. Raymond C. Browning and Rodger Kram: Energetic Cost and Preferred Speed of walking in Obese vs. Normal Weight Women: OBESITY RESEARCH Vol. 13 No. 5 May 2005 891- 899. 